\title{
Flow past a Groove
}

\author{
Kern E. Kenyon \\ 4632 North Lane, Del Mar, USA \\ Email: kernken@aol.com
}

Received 6 February 2015; accepted 24 February 2015; published 27 February 2015

Copyright (C) 2015 by author and Scientific Research Publishing Inc.

This work is licensed under the Creative Commons Attribution International License (CC BY).

http://creativecommons.org/licenses/by/4.0/

(c) (7) Open Access

\begin{abstract}
Based on available evidence, it is hypothesized that the net force of friction on a flat solid wall, when fluid flows steadily along it, is reduced by putting one or more grooves in the wall's surface oriented perpendicular to the mean flow. Among the convincing observations are the existence and history of golf balls which show that golf balls with dimples travel farther than golf balls without dimples. Also there is a laboratory experiment using streak photography of low Reynolds number flow along a straight wall with a square cavity in it, illustrating that the flow jumps right across the cavity's opening, strongly suggesting that there is no friction of the fluid on the wall in the region of the cavity. One forecast is that if grooves or dimples are made on the inside surface of pipes, the discharged rate of the pipe for fluid flow should become increased.
\end{abstract}

\section{Keywords}

Flow past a Groove, Reduced Friction

\section{Introduction}

Golf balls have dimples for a good reason, which can be traced back to an accidental discovery in the mid-1800s [1]. When small scrapes or nicks occurred in the surface of the ball, observations showed that there was an increase in the distance the ball traveled. By the early 1900s, all golf balls were manufactured with dimples. Is that basically the end of the story? What is the root cause of this phenomenon? Apparently there are available no other practical applications of the idea behind the dimples of present day golf ball?

Suppose that, driven by some unspecified force, steady flow of a constant density fluid moves along a flat rigid wall and then encounters a bump in the wall. The bump's specific shape is not important, but for convenience small slopes will be assumed. Of necessity the fluid next to the bump must rise up the forward face because of the boundary condition that fluid cannot penetrate the solid surface of the bump. Then consider a steady flow along a flat rigid wall that comes to a dip (inverse bump) in the wall. There is no corresponding necessity that the fluid adjacent to the wall follow the surface downward on the front face of the dip. In general, one would not expect such a thing to happen. Note that the upward and downward directions mentioned here have nothing to 
do with the action of gravity being significant or not.

In searching through the nine fairly standard fluid dynamics books on my shelf for information on flow past a groove, I found only one text with one paragraph on the subject in it: [2]. However, on the previous page is a very interesting photograph to go with this paragraph. Streak photography was used to illustrate flow at low Reynolds number along a solid flat wall that had a square cavity in it. The depth of the cavity was comparable to its width. Assume that the flow was from left to right (the text doesn't say but the reference cited undoubtedly does [3]; it is not important for the present purpose). It is seen that the flow along the wall continues right across the opening of the cavity and then goes along the wall again on the other side of the cavity. Although not totally counter-intuitive, such an observation is just a bit surprising. Deductions that arise from this observation are given below.

\section{Groove Opening}

To begin with, understanding how the flow can go across the groove's opening needs to be addressed and hopefully understood better. Since the flow appears in the photograph to be steady, the streaks make the streamlines visible. Along a streamline Bernoulli's law is expected to hold approximately: where the speed is greatest the pressure is least. Thus, across the opening the pressure in the flow is lower than just below the flow in the cavity. Although it is seen in the photograph that the flow dips down a small amount at the entrance of the cavity, it is prevented from going further into the groove by the upward pressure gradient holding the flow up.

Strictly speaking Bernoulli's law is not valid when friction is involved. However, across the gap friction within the fluid is less than friction between fluid and solid along the wall because vertical velocity gradients will be less in the groove where there is no non-slip boundary condition within the opening. Also the friction term to be added to Bernoulli's law is small if the curvature of the streamlines is small [4], which it is at the groove's opening according to the streak photograph.

\section{Deductions}

An elementary theoretical (analytical) model of flow past a groove appears to be out of reach at present and no such model already exists as far as I can determine. Numerical techniques may be brought into service on the problem in the future, however. Of course further observations are always welcome. In the interval a few important deductions can be put forward based on the existing evidence.

First, it is self-evident from the streak photograph mentioned above that friction between the fluid and the solid wall will not only be small in the region of the groove, compared to that on the flat wall on either side of the groove, but it may actually have the opposite sign, since there appears to be a weak recirculation within the groove. In other words, at the bottom of the groove the friction force probably points upstream! Confirmation by observations of the reduction in friction by the presence of a groove is badly needed. This possible outcome of the effect of a groove on the total friction of the fluid on the wall was not mentioned in the above reference [2].

Second, if one groove reduces the net friction on the wall, even by a tiny fraction, then more grooves should reduce friction by a greater amount. For example, assuming friction reduction is their main purpose, there are about as many dimples on a golf ball as can be fitted in: well over one hundred [1].

\section{Discussion}

During translation through the air a golf ball almost always rotates about an axis that passes through the ball, the way the game is normally played. That introduces another force into the problem: the sideways acting Magnus effect. Then confusion can enter because the Magnus effect does have an influence on the distance the ball travels. If a golf ball can be struck without rotation, and if a ball with dimples consistently travels farther than a smooth ball, a stronger case could be made that the dimples reduce the friction between the air and the ball.

While waiting for experimental verification of the two deductions stated above about friction reduction by grooves in a solid boundary, one other application can be hazarded. Dents could be placed on the inside surface of pipes to see if the discharge rate increases. Or circular grooves could be made inside in planes parallel to vertical cross-sections of the pipe, whichever would lead to the greater result or be easier to make or both.

\section{Conclusion}

It is concluded that a flat solid wall experiences less friction from a fluid flowing next to it if there are one or 
more grooves cut into the wall's surface in the direction normal to the mean flow. Laboratory observations strongly suggest that the conclusion is valid but further measurements are needed to confirm it. Assuming the conclusion is right, then it should also be true that a pipe will have a greater discharge rate of fluid flow when grooves are cut into the inside surface.

\section{References}

[1] Pickover, C.A. (2011) The Physics Book. Barnes \& Noble, New York, 298.

[2] Tritton, D.J. (1988) Physical Fluid Dynamics. Oxford Science Publications, Clarendon Press, Oxford, 146-147.

[3] Taneda, S. (1979) Visualization of Separating Stokes Flows. Journal of the Physical Society of Japan, 46, $1935-1942$. http://dx.doi.org/10.1143/JPSJ.46.1935

[4] Milne-Thomson, L.M. (1955) Theoretical Hydrodynamics. 3rd Edition, Macmillan, New York, 571-572. 
Scientific Research Publishing (SCIRP) is one of the largest Open Access journal publishers. It is currently publishing more than 200 open access, online, peer-reviewed journals covering a wide range of academic disciplines. SCIRP serves the worldwide academic communities and contributes to the progress and application of science with its publication.

Other selected journals from SCIRP are listed as below. Submit your manuscript to us via either submit@scirp.org or Online Submission Portal.
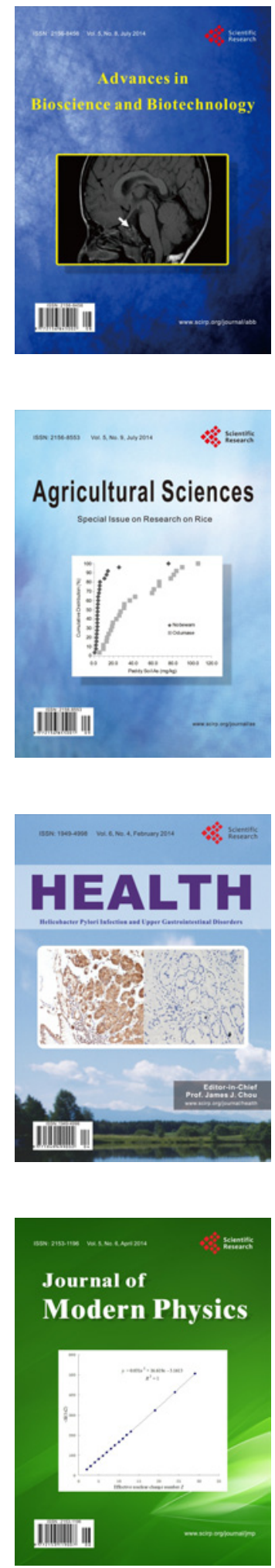
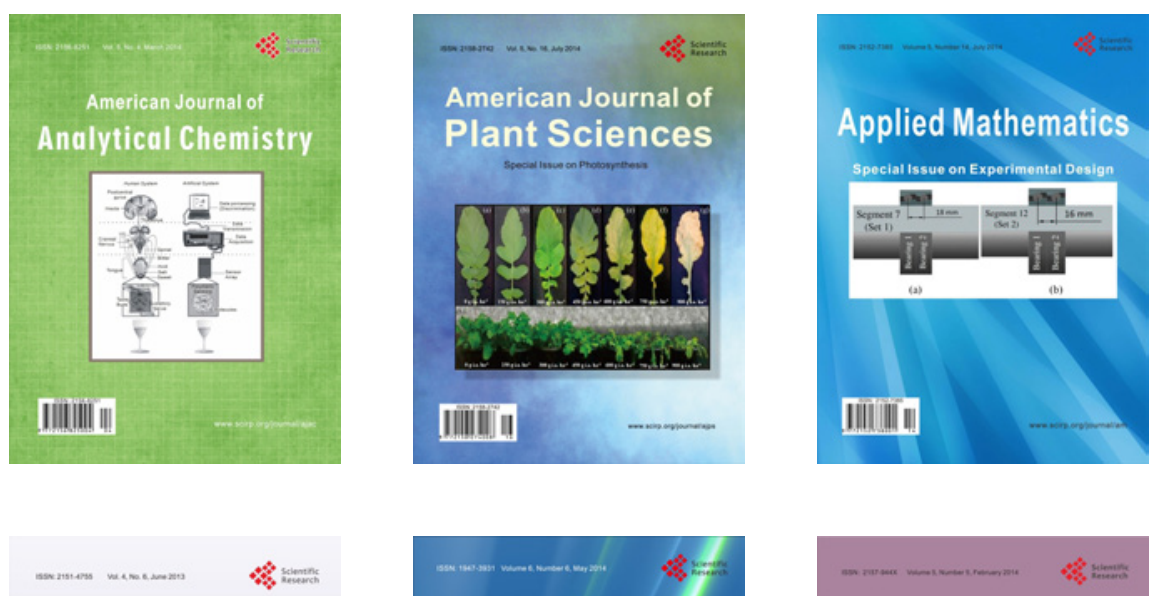

Creative Education
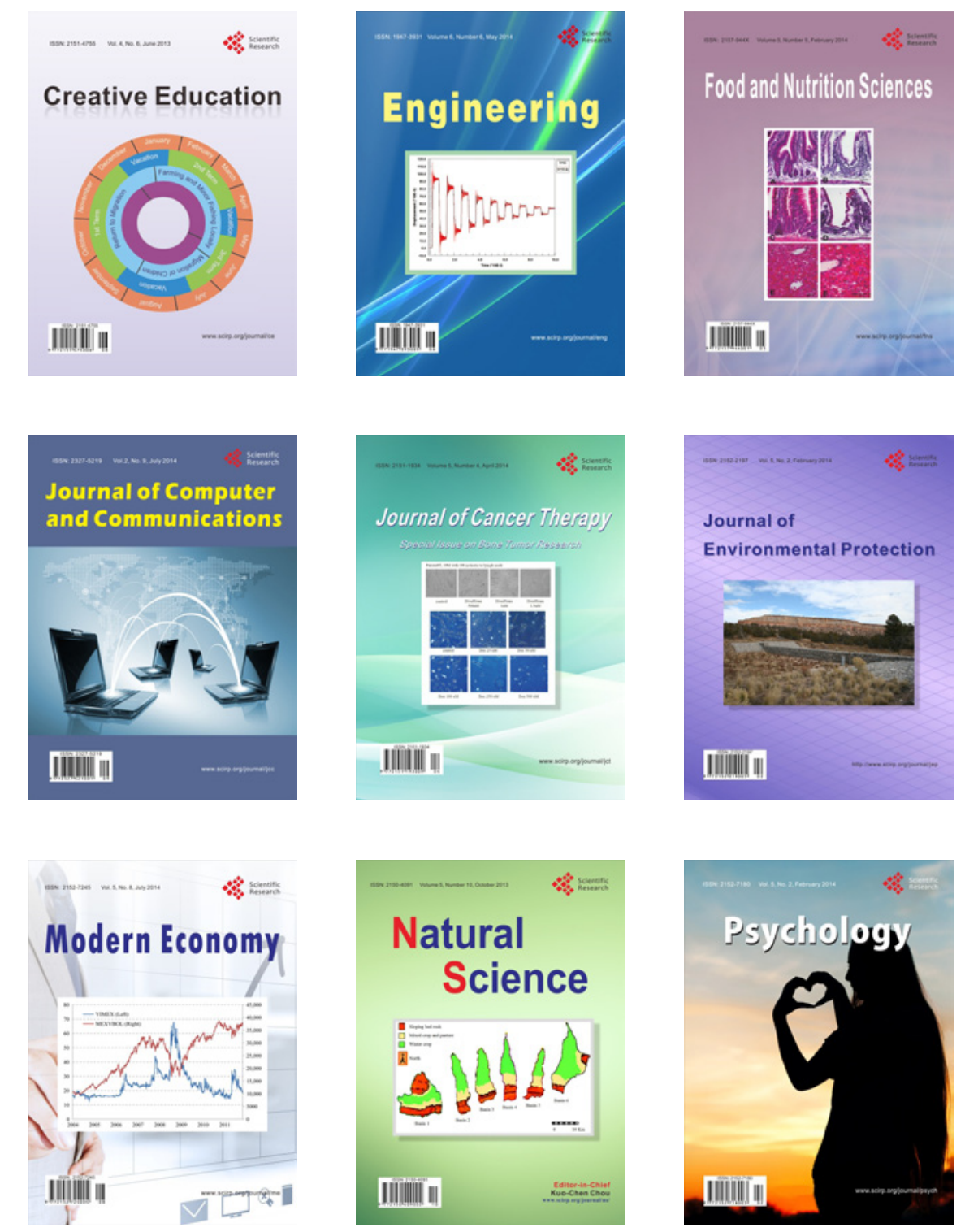